\title{
Commentary: Should we use a "full metal jacket" after repair for chronic residual type I aortic dissection?
}

\author{
Francois Dagenais, MD
}

\author{
From the Department of Cardiac Surgery, Institut Universitaire de Cardiology et Pneumologie de Québec, \\ Québec, Québec, Canada. \\ Disclosures: Author has nothing to disclose with regard to commercial support. \\ Received for publication July 15, 2019; accepted for publication July 17, 2019; available ahead of print Aug 13 , \\ 2019. \\ Address for reprints: Francois Dagenais, MD, Institut Universitaire de Cardiology et Pneumologie de Québec, \\ 2725 chemin Sainte-Foy, Québec, Québec, Canada G1V4G5 (E-mail: francois.dagenais@ @ chg.ulaval.ca). \\ J Thorac Cardiovasc Surg 2019;158:1017-8 \\ $0022-5223 / \$ 36.00$ \\ Copyright (c) 2019 by The American Association for Thoracic Surgery \\ https://doi.org/10.1016/j.jtcvs.2019.07.032
}

In the current issue of the Journal, Huang and colleagues ${ }^{1}$ tackle the difficult clinical problem of aortic remodeling after repair for chronic residual type I aortic dissection. They analyzed retrospectively 2 non-contemporary groups of patients treated either with a frozen elephant trunk or an aortic debranching procedure without bare metal stents (BMS) $(\mathrm{N}=27$; 4.4 years follow-up) or with BMS $(\mathrm{N}=20$; 1.8 years follow-up) extension. Both groups had similar lengths of covered stents within the thoracic aorta, whereas uncovered dissection stents were added down to the aortic bifurcation in the BMS group. The primary objective was to compare the fate of the thoracic and abdominal true lumen (TL) and false lumen (FL) at 1 year. The authors reported similar TL expansion and FL thrombosis in the thoracic segment, although a significant decrease in stent graft-induced new entry (SINE) tear incidence was observed after the first year of follow-up in the BMS group. Within the abdominal segment, a significant increase in abdominal TL volume was seen in the BMS group. However, 1-year abdominal FL volume was similar in both groups, although a greater rate of FL thrombosis was detected in the BMS group.

Treatment of residual chronic type I aortic dissection remains a significant challenge. The classic 2-stage open approach is associated with a high mortality and morbidity, although excellent early- and long-term results are reported in good operative candidates. The introduction of thoracic endovascular aortic repair in the late 1990s revolutionized the treatment of type B dissection, setting new gold standards, especially in cases of malperfusion. Furthermore, thoracic endovascular aortic repair in acute type $\mathrm{B}$ dissection showed significant positive aortic remodeling in the thoracic aorta; remodeling improved by the adjunct of the Petticoat technique, although the mid- to long-term benefit of the Petticoat technique still needs to be proven in the setting of acute aortic dissection. $^{2,3}$ With the development of frozen elephant trunk

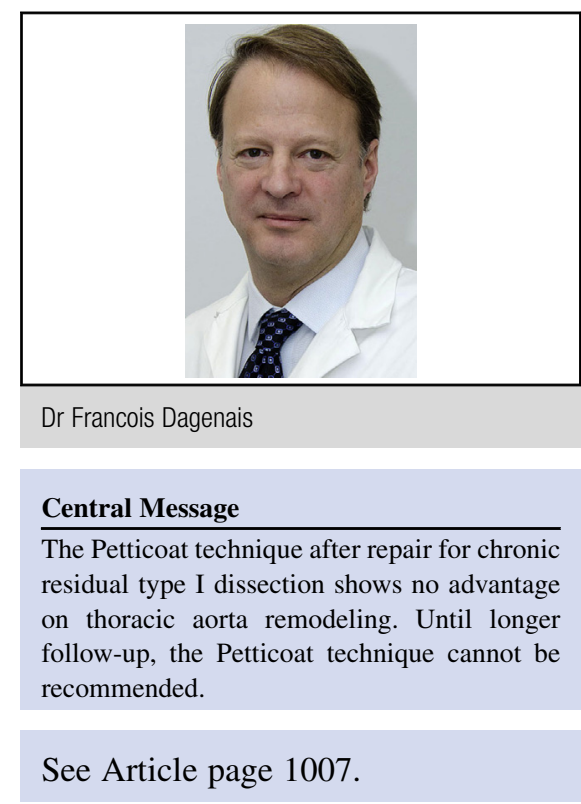

and hybrid arch debranching techniques, new strategies emerged to treat residual chronic type I aortic dissection with less morbidity and mortality. However, a significant proportion of patients remained with significant thoracic FL perfusion and aortic expansion. ${ }^{4}$ Strategies to force the FL thrombosis using coils or other embolization devices have been encouraging. ${ }^{5}$

Huang and colleagues ${ }^{1}$ suggest using the Petticoat technique to expand the thoracoabdominal TL and promote the FL thrombosis. Unfortunately, no significant advantage was observed in the thoracic aorta. Noteworthy is the mean stented coverage length of $20 \mathrm{~cm}$ in both groups with a $90.6 \%$ thrombosis rate in the non-BMS group, which may in part explain the comparable outcomes in the thoracic aorta. Although the favorable prognosis of FL thrombosis in the thoracic aorta is well documented, the impact of FL thrombosis/patency ratio in the abdominal aorta remains unclear. Furthermore, procedure-related complications with the Petticoat technique are reported. Complex concomitant endovascular procedures may be required to salvage visceral vessels, especially when perfused by the FL. Within the present study, only 3 visceral arteries were perfused by the FL in the BMS group. Furthermore, late complication such as stent fracture requiring emergent intervention has been reported with BMS. ${ }^{6}$ Although the incidence of SINE has been reported to be lessened with the Petticoat technique, the greater incidence in SINE 
observed in the non-BMS group in the present study may be related to the significant graft oversizing within the nonBMS group (1.4 in BMS vs 2.0 in non-BMS). Emerging new graft technology with tapered configurations or differential radial force may allow to decrease SINE without the use of BMS.

Huang and colleagues ${ }^{1}$ have to be congratulated for their contribution to a difficult subset of patients. However, since no positive remodeling was observed in the thoracic aorta, the use of the Petticoat technique in chronic dissection post type I repair cannot be recommended. Longer follow-up will allow us to assess the potential advantages of the remodeling observed in the abdominal aorta. Furthermore, better classification of chronic residual type I aortic dissection such as the site of major re-entry tears will allow to better compare operative strategies and outcomes.

\section{References}

1. Huang C-Y, Hsu H-L, Chen P-L, Kuo T-T, Chen I-M, Hsu C-P, et al. Aortic remodeling after hybrid provisional extension to induce complete attachment aortic repair of chronic residual type I aortic dissection. J Thorac Cardiovasc Surg. 2019;158:1007-16.

2. Sultan I, Dufunbach K, Kilic A, Bianco V, Trivedi D, Althouse AD, et al. Bare metal stent use in type B aortic dissection may offer positive remodeling for the distal aorta. Ann Thorac Surg. 2018;106:1364-70.

3. Bertoglio L, Rinaldi E, Melissano G, Chiesa R. The PETTICOAT concept for endovascular treatment of type B aortic dissection. J Cardiovasc Surg (Torino). 2019;60:91-9.

4. Rohlffs F, Tsilimparis N, Diener H, Larena-Avellaneda A, Von Kodolitsch Y, Wipper S, et al. Chronic type B dissection: indications and strategies for treatment. J Cardiovasc Surg (Torino). 2015;56:231-8.

5. Pellenc Q, Roussel A, De Blic R, Girault A, Cerceau P, Ben Abdallah I, et al. False lumen embolization in chronic aortic dissection promotes thoracic aortic remodeling at midterm follow-up. J Vasc Surg. March 5, 2019 [Epub ahead of print].

6. Duque Santos Á, Reyes Valdivia A, Gordillo Alguacil S, Ocaña Guaita J, Gandarias Zúñiga C. Symptomatic aortic bare-metal stent fracture after Petticoat technique for complicated type B aortic dissection. Ann Vasc Surg. February 23, 2019 [Epub ahead of print]. 